Session 1420

\title{
A PROGRAM FOR STUDENT EDUCATION AND EVALUATION OF PERSONAL DIGITAL ASSISTANTS
}

\author{
Charles McIntyre, Prajesh Kondaskar, and Gary Smith \\ Civil Engineering and Construction \\ North Dakota State University
}

Introduction

During the summer of 2002, Steve Nellis, Vice-President of Recruiting for Centex Homes (Dallas, Texas) issued a call for proposals from a number of colleges and universities offering programs in construction engineering and/or construction management. The proposal consisted of an offer from Centex Homes to provide a number of Personal Digital Assistants (m105 Palm) to select construction programs throughout the country. Their intention was to provide the students with an example of the type of tools that are used in the day-to-day operations of the home building industry. A limited number of m105 Palms were available. The exact number distributed to each applicant was dependent on the requested use and student interest. On average each applicant received ten (10) m105 Palms. The units were shipped on July 15, 2002, in time for the start of the 2002 Fall Semester. The Division of Construction Management and Engineering (CME) at NDSU applied for, and received, 10 PDAs. The contents of this paper:

1.) describe the Palm Education and Evaluation Program (PEEP),

2.) provide an overview of the student use of the Palm functions,

3.) give a breakdown of the learning strategies that were employed by the students, and

4.) document student assessment in the form of comments that were summarized from the interim reports (2002 Fall Semester), and 5.) present conclusions.

The Proposal

The initial proposal sent to Centex Homes attempted to: 1.) formalize the PDA distribution to the students based on merit, 2.) document the student learning processes involved with PDA technologies, and 3.) evaluate and assess the overall PDA program. After receiving the PDAs from Centex Homes, 
the initial proposal was modified for student use (as explained later). During the 2002 Fall Semester, interested CME students in good academic standing were invited to develop a written proposal requesting that they be considered for inclusion into the "Palm Education and Evaluation Program" (PEEP). In order to receive a m105 Palm, each student had to clearly describe their individual proposed PDA learning strategies and their specific intended academic or industry applications for PDA use. Once selected, they had to sign a written contract for the loan of the Palm, as well as, specify their intended educational objective. Two options were available: A.) research uses and applications of PDAs, specifically Palm applications that have been developed for construction management and engineering or B.) research uses and applications of PDAs, specifically Palm applications that have been developed for academic (i.e., student learning) purposes (and could possibly be adopted and used within the CME program). The students were required to attend bimonthly meetings and to submit two written reports, an interim report due at the end of the Fall Semester and a final report at the end of the Spring Semester. The call for student proposals for the Palm Education and Evaluation Program is outlined in Appendix A.

Based on the student response to the request for proposals, the CME Division decided to accept twelve (12) students into the PEEP program, eleven (11) undergraduate students and one (1) graduate student. The CME Division purchased an additional two m105 Palms to account for the two additional students accepted into the PEEP program.

The application from the graduate student included a proposal to further explore the use and potential of PDA technologies and to actually turn his expanded research into an M.S. thesis. The main objective of the graduate proposal was to determine how PDAs wireless units can be used to increase and improve project management functions and communications between the home and field offices. Several case studies will be used to study, analyze, and document the issues encountered by the personnel in using these devices and offer suggestions for improved project management, as well as, enhancements to some of the features provided in PDAs, in order to provide a more effective management and communication tool.

Each student was required to complete and sign the PEEP Loan Agreement, which basically established a contract between each student and the CME Division (refer to Appendix B: PEEP Loan Agreement Contract).

\section{Palm Functions}

The following table lists the Palm functions that were used by the students. The number in the Student Use column refers to the actual number of students that used that particular function of the Palm (the total number of students enrolled in the program was twelve). 
Table 1. Palm Functions vs. Student Use

\begin{tabular}{|l|c|}
\hline \multicolumn{1}{|c|}{ Function } & Student Use \\
\hline Date Book (use to plan \& schedule events) & 11 \\
\hline Address Book (store contact information) & 12 \\
\hline Note Pad (write notes and brief documents) & 8 \\
\hline "To Do" List (track tasks by date, category, \& priority) & 9 \\
\hline Graffiti Writing (Palm hand writing system by stylus) & 7 \\
\hline Download Programs and Games (from Internet) & 12 \\
\hline Wireless Transmission (Beaming Data - IR Port) & 9 \\
\hline Hot Sync ( Synchronize between Palm and Computer) & 7 \\
\hline
\end{tabular}

\section{Palm Learning Strategies}

There were four basic Palm learning strategies that were used by the students of the PEEP program:

A) Trial and Error: A hands on approach used by students to experiment with the Palm functions.

B) Reference Manual - "Getting Started m100 Handheld Series" (included with the Palm m105): A quick and easy reference for using the Palm features.

C) Palm Tutorial (on-line): The same information as contained in the Reference Manual but in electronic format.

D) Peer to Peer: Informal group meetings of two or more students to discuss palm issues and exchange programs.

The following table illustrates the type of learning strategies that were employed by the students of the PEEP program. The number in the Student Use column refers to the actual number of students that used a particular learning strategy or combination of strategies. The data was collected from the Interim Reports that were due at the end of the 2002 Fall Semester. The data suggests that the predominant learning strategies were Trial and Error and Peer to Peer. 
Table 2. Learning Strategies vs. Student Use

\begin{tabular}{|c|c|}
\hline Learning Strategies & Student Use \\
\hline A. Trial and Error (only) & 1 \\
\hline B. Reference Manual (only) & 0 \\
\hline C. Palm Tutorial (only) & 0 \\
\hline D. Peer to Peer (only) & 0 \\
\hline A \& D & 2 \\
\hline A, C, \& D & 8 \\
\hline A, B, C, \& D & 1 \\
\hline
\end{tabular}

Student Comments and Observations

The following comments were extracted and summarized from the Interim Reports submitted at the end of the 2002 Fall Semester. These comments, along with the faculty assessments (due at the end of the 2003 Spring Semester), will assist with PEEP program assessment.

"To learn how to use the Palm m105 I just started playing around with it. To me it is just like a mini computer with a pen for a mouse. I decided that my learning strategies for it were going to be just to plug and play and see what I was able to do with it. The more I used it the better I understood what it could do."

"I have found the m105 to be quite beneficial in my eyes. By using the calendar and to-do list I was able to make sure I never forgot anything. Using the Palm next semester will help out quite a bit, since I will have more projects and more group meetings in the spring."

"Having had brief opportunities to use Palm in the past, I was already familiar with its basic operation. Even though I found that the Palm was easy to operate from the start, I did have to use the manual to figure at one or two operations, especially when learning how write each characters. For the most part, the majority of knowledge came from trial and error."

"Overall I am very happy with the PEEP program. Even though I have only had it for a couple of months, I have become very dependent on it. It is much easier for me to keep track of tasks, errands, and dates. I feel that my life is much more organized." 
"The PDA was a very good tool in helping me to become more organized. I used the date book for assignments, meetings, appointments, etc. I hope to continue to wean myself from the typical note on paper to the Palm."

"For personal planning and organizing, it does not work for me. I still do much of my personal scheduling by hand. Perhaps I have not put enough time into learning the system."

"I no longer have to carry my calculator, notepad, and organizer as the Palm m105 serves all those purposes. Thus the PDA has helped me a lot in efficiently managing and performing my daily tasks in school during the semester. I personally feel that using PDA this semester has helped me a lot in achieving my academic goals."

"I feel that using the Palm has helped me become better organized with both school and my personal life. I tend to always know where my Palm is and usually carry it with me no matter where I go. If I hadn't been given this opportunity to use a Palm this year I probably would have bought one. As I have become better acquainted with the functions of the Palm, I see myself using it for most everything that I do and getting rid of using paper planners and post-it notes."

"For me this project has proven itself extremely useful in developing new ways to schedule, manage, and consolidate everyday tasks. At this point I would recommend strongly to consider it for all incoming students."

"Some of the software applications that I have on my Palm are just for fun, while others are quite impressive. The fun ones are things like Mahjong tiles and Bejeweled for the Palm. The more impressive ones are the applications you can download such as documents to go, which has a Word type program along with a Slide Show program and an Excel type program. I also found a great bankbook program that I now use as my check book register and then all I have to do is write down my balances in my checkbook because the Palm takes care of all of the addition subtraction and keeping track of check numbers and the types of transactions."

Summary

The PEEP program has attempted to document student uses and applications for personal digital assistants (Palm m105). A formal process has been initiated which, 1.) establishes a contract between the student and the CME Division, 2.) documents the functions and learning strategies that were used by the students, and 3.) assesses the overall PEEP program.

From the periodic meetings held with the students during the 2002 Fall Semester and after reviewing the interim PDA reports submitted by students, it was observed that out of the four basic learning strategies 
employed (A through D) that the Peer to Peer learning strategy was the most helpful. The final assessment for PEEP will actually be completed after the final student reports are submitted at the end of the 2003 Spring Semester. Additional results and conclusions of the PEEP program will be presented at the 2003 American Society for Engineering Education Annual Conference \& Exposition in Nashville, TN in June.

Bibliography

1. “Getting Started m100 Handheld Series” Palm Inc., Santa Clara, CA, 2000.

2. http://www.palm.com

3. http://www.palm.net

Biographies

Charles McIntyre is an Assistant Professor in the Department of Civil Engineering and Construction at North Dakota State University. Dr. McIntyre is an advanced FIEL fellow and has developed several faculty seminars dedicated to enhancing student learning. He attended the PBL workshop at the University of Delaware and has worked on implementing PBL into his course offerings. Dr. McIntyre has received several awards and university recognition for teaching efforts.

Prajesh Kondaskar is a graduate student in the Department of Civil Engineering and Construction at North Dakota State University. His research work will focus on the functions and uses of PDAs in the construction industry.

Gary Smith is a Professor and CME Division Head in the Department of Civil Engineering and Construction at North Dakota State University. 
Appendix A : Call for student proposals for the Palm Education and Evaluation Program

"Palm Education and Evaluation Program (PEEP)" 2002-3

Construction Management and Engineering

North Dakota State University

To all Sophomore, Junior, and Senior Construction Management and Engineering students in good standing:

Centex Homes recently contributed ten m105 Palms to the Division of Construction Management and Engineering. Their objective is to have students gain experience with the tools they employ on projects. These PDAs will be loaned to CME students in good standing on the basis of their response to this request for proposals for the 2002-2003 Academic Year. In order to qualify a Palm (m105), you must submit a proposal to Dr. Charles McIntyre and Dr. Gary Smith by Friday, September 13, 2002 at 5:00 p.m. (electronic submissions only).

Required Proposal Elements

Included in the request must be detailed information on:

a) Have you used a Palm or similar personal data assistant (PDA)?

b) How you plan to use the Palm (what will you do with it)?

c) How will it help in your course work?

d) How do you think it will help you become better organized, etc.

e) Type of application and research on applications for education and/or practice you would like to do. (See Option A or B below).

Faculty will review the applications and rate on the basis of clarity and proposed uses for the PDA. There will be five (5) PDAs made available for Option A and five (5) for Option B. If you are one of the successful applicants, you agree to participate in periodic meetings and submit an interim and a final report (described in the agreement form). 
Appendix B : PEEP Loan Agreement Contract

\section{PEEP Loan Agreement Contract}

Construction Management and Engineering

North Dakota State University

\section{Interim Report (Due the last day of the Fall Semester)}

How did you learn to use the Palm m105? Give a detailed explanation concerning the learning strategies that you used (on-line help, chat rooms, paper-based manuals, peer/group learning, formal instruction at Information Technology Services (ITS), self taught - trial and error, etc.). Describe how you used the PDA in school applications. (personal organizer, class activities, course work, web access, e-mail, software applications, timekeeper / reminder, date/address book, calculator, memo / note pad, data access / storage, games, etc.). How is the Palm experience beneficial from your perspective?

\section{Spring Semester and Final Report (Due the last day of the Spring Semester)}

Update your interim report based on comments or questions from faculty and provide additional input for the questions listed above for the Fall Semester. One additional question for the final report: What would you have done differently or what suggestions do you have for improving/maintaining the PEEP program? Select and report your findings on either of the following topics:

A) Research uses and applications of PDAs (Palm Applications) that have been developed for construction management and engineering.

B) Research uses and applications of PDAs (Palm Applications) that have been developed for learning (academic) purposes that could be used in the CME program.

The final report must be submitted in the form of an electronic document (M.S. Word, Word Perfect, PDF, etc.). Submit the final reports to Dr. McIntyre (charles.mcintyre@ndsu.nodak.edu). Return Equipment: Last day of the Spring Semester -- students are responsible for the equipment loaned. Lost or damaged units will be replaced at the student's expense.

My signature to this agreement indicates I am willing and able to complete the assignments as described above in a timely manner and I will return the PDA assigned to me at the completion of the 2003 Spring Semester.

You have been assigned to OPTION: A or B (faculty will circle one)

(Signature)

(Date)

PDA SERIAL NUMBER: (issued by faculty) 